José Fernández Richard*

\title{
Facultad de los Municipios para poner término anticipado a las concesiones que otorga
}

\section{Resumen}

1.- Facultad de los Municipios para otorgar determinadas concesiones. 2.- Casos en que las Municipalidades pueden poner término anticipado a la concesión: circunstancias en que procede indemnización. 3.- Jurisprudencia. 4.-Conclusiones.

\section{Palabras clave}

Municipio, concesiones, indemnización, jurisprudencía.

Profesor Derecho Urbanistico U. de Chile

Profesor Derecho Administrativo, Derecho Municipal y Derecho Urbanistico

Universidad Pedro de Valdivia Ex abogado integrante Corte Suprema.
Art. 118 inc. 42 C. Política.

Art. $1^{\circ}$ Ley 18.695 Orgánica Constitucional de Municipalidades.

Art. 3, 4 y 5 ley 18.695 Orgánica Constitucional de Municipalidades.

Art. 8०Ley 18.695. 
concesiones sobre bienes municipales o nacionales de uso público, que administre la municipalidad $^{5-6}$.

3.- Las referidas concesiones se rigen por las normas de la ley orgánica constitucional de municipalidades -Ley 18.695-y además por los preceptos de la Ley 18.575 sobre Bases Generales de la Administración del Estado y de la Ley 19.880 sobre Procedimientos Administrativos.

4.- Las concesiones se otorgan previa licitación pública, si el total de los derechos o prestaciones que deba pagar el concesionario sea superior a cien unidades tributarias mensuales ${ }^{7}$, lo que obliga a los municipios a elaborar Bases y efectuar públicos llamados.

5.- Mediante este sistema los municipios no solo han concesionado servicios como el de extracción de basura, cuidado de plazas y jardines públicos, sino que han podido a través de concesiones construir estacionamientos subterráneos, siendo de cargo del concesionario la construcción y la posterior explotación. Esto ha ocurrido en numerosas comunas del gran Santiago, p. ej. Providencia, Las Condes, Santiago, etc.

Todo lo anterior ha sido motivo de progreso para las comunas, pero ha ocurrido que a veces el servicio concesionado no se presta en las condiciones previstas, o se efectúa en forma deficiente, generándose incumplimientos, lo que fuerza al municipio a poner término anticipado a la concesión, como veremos más adelante.

\section{Casos en que las municipalidades pueden poner término anticipadoa la concesión. Circunstancia en que procede indemnización}

1.- El artículo $8^{\circ}$ de la Ley 18.695 establece la facultad de los entes edilicios de otorgar concesiones ya sea para la prestación de determinados servicios municipales, para la administración de establecimientos o de bienes específicos que posean o tengan a cualquier título. Esta facultad se ejerce llamando a licitación pública, requiriendo al Alcalde el acuerdo del Concejo Municipal ${ }^{8}$, pero nada nos dice el precepto del art. $8^{\circ}$ acerca de los casos en que el municipio puede poner término a la concesión. Esta materia la trata separadamente en el párrafo $5^{\circ}$ del título I, que se refiere al "Régimen de bienes”, y específicamente la contempla en el artículo 36 de la Ley 18.695.

2.- El artículo 36 de la Ley 18.695 en su primer inciso contempla la facultad de las Municipalidades de otorgar concesiones y permisos sobre los bienes municipales o nacionales de uso público, incluido el subsuelo. En el inciso $2^{\circ}$ se efectúa la distinción

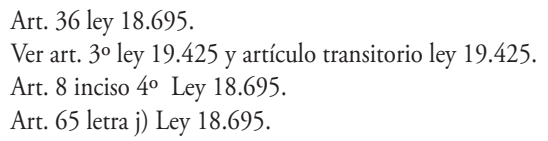


entre concesiones y permisos, siendo estos últimos esencialmente precarios, pudiendo ser modificados o dejados sin efecto, sin derecho a indemnización. ${ }^{?}$

En el tercer inciso del artículo mencionado el legislador se refiere expresamente a que si bien las concesiones darán derecho al uso preferente del bien concedido, en las condiciones que fije la Municipalidad, "ésta podrá darle término en cualquier momento, cuando sobrevenga un menoscabo o detrimento grave al uso común o cuando concurran otras razones de interés público".

3.- El precepto antes transcrito se basa obviamente en razones de interés general de la comunidad, en que debe primar el interés público por sobre el interés particular del concesionario. Lo importante es que cuando se invoque este precepto existan antecedentes ciertos y fidedignos que le permitan demostrar al municipio que efectivamente se ha producido un menoscabo o detrimento grave al uso común o que concurren otras circunstancias que comprometen el interés público. Cualquier divergencia sobre esta materia tendrá que ser resuelta por los Tribunales de Justicia, quienes podrán conocer de la contienda vía el recurso de protección que contempla el art. 20 de la Carta Fundamental, o a través del reclamo de ilegalidad que establece el art. 140 de la Ley 18.695 .

4.- Ahora bien, puede suceder que tanto el municipio como el concesionario están contestes, acerca de que se han producido las circunstancias que facultan al ente edilicio para poner término a la concesión. En este caso no se produce contienda alguna y no es necesario llevar el conocimiento y resolución de este asunto a estrados judiciales. Sin embargo queda pendiente un punto, a saber: ¿ Procede indemnización al concesionario, cuando se le pone término anticipado a su concesión? La respuesta es afirmativa, ya que existe texto expreso contenido en el inciso $4^{\circ}$ del mencionado art. 36 de la Ley 18.695 que señala textualmente:

5.- "El concesionario tendrá derecho a indemnización en caso de término anticipado de la concesión", agregando: "salvo que éste se haya producido por incumplimiento de las obligaciones de aquel".

6.- Sobre la materia cabe hacer algunas observaciones: a) Queda suficientemente claro que a no mediar incumplimiento de las obligaciones del concesionario, procederá siempre la indemnización por término anticipado; b) El legislador se refiere al incumplimiento en forma genérica. No exige que sea grave. Normalmente en las Bases de la Licitación, que constituyen parte integrante del contrato de concesión, se gradúan los incumplimientos, y algunos de ellos que se refieren a aspectos secundarios, que no influyen mayormente en la marcha de la concesión, son sancionados con simples multas. La jurisprudencia, como veremos más adelante, se ha pronunciado indirectamente sobre este punto, ateniéndose a si las Bases Administrativas de la licitación califican ciertos hechos como incumplimientos graves. Si así lo estiman, ese incumplimiento justifica el término anticipado de la concesión, sin derecho a indemnización; c) Puede ocurrir que

9 Ver “Derecho Municipal chileno”. José Fernández Richard, año 2003 y 2007. Edit. Jurídica de Chile. 
las partes -esto es municipio y concesionario- estén de acuerdo en las circunstancias fácticas que hacen procedente el término anticipado, pero no tengan igual consenso en cuanto al monto de la indemnización. Ello no lo podría resolver unilateralmente el Municipio, ya que al hacerlo actuaría de Juez y Parte, ejerciendo una autotutela, lo cual no es lícito, por lo cual esta controversia tendría que ser resuelta por los Tribunales Ordinarios de Justicia. Aquí no se presenta un problema de calificación sino que una materia de cuantificación de una indemnización, en que habiendo acuerdo en cuanto a su procedencia, no existe el mismo consenso en cuanto a su monto; d) Este tema de la procedencia o no del término anticipado de la concesión y de su eventual indemnización, se encuentra tratado en el art. 36 de la Ley 18.695 que se refiere a las concesiones en bienes municipales o bienes nacionales de uso público que administre la Municipalidad. ¿Qué ocurre cuando se trata de otro tipo de concesiones, como son aquellas de servicios municipales o establecimientos de igual índole, a que se refiere el art. $8^{\circ}$ de la Ley 18.695 ? El art. $8^{\circ}$ ya mencionado no dice nada al respecto, por lo cual creemos que en primer lugar habrá que estarse a las estipulaciones contenidas en las Bases Administrativas de la licitación, que forman parte integrante del contrato de concesión, y en segundo término aplicar los principios contenidos en el art. 36 de la Ley 18.695, lo cual no es una aplicación por extensión o analogía sino que simple aplicación de "principios generales de Derecho", que se encuentran contenidos en numerosas normas de nuestro ordenamiento jurídico y especialmente en el Código Civil, al tratar de las obligaciones en su Libro IV; e) Es de interés señalar que el art. 37 de la Ley 18.695 al referirse a las concesiones sobre el subsuelo, reglamenta en forma específica las causales de extinción de este tipo de concesiones y señala 3 causales: 1.- cumplimiento del plazo por el que se otorgó; 2.- Incumplimiento grave de las obligaciones impuestas al concesionario, y 3.- mutuo acuerdo entre la municipalidad y el concesionario. Estimamos que aquí nos encontramos con una norma especial aplicable a las concesiones sobre el subsuelo, y que debe aplicarse con preferencia al precepto contenido en el art. 36 de la Ley 18.695. Este alcance no es menor, ya que al contrario de lo que ocurre en el art. 36, en el art. 37 para poner término a la concesión se requiere en forma expresa que el concesionario haya incurrido en un "incumplimiento grave" y no en cualquier clase de incumplimiento, como parece dar a entender aparentemente el art. 36 del referido cuerpo legal; f) no está demás señalar que el Alcalde no puede por sí y ante sí poner término anticipado a la concesión, ya que requiere el acuerdo del Concejo Municipal ${ }^{10}$.

\section{Jurisprudencia}

1.- Existe numerosa jurisprudencia sobre el tema que hemos desarrollado en el curso de este estudio, todo ello coincidente con los principios que someramente hemos esbozado. 
En esta oportunidad estimamos de mayor utilidad referirnos a la jurisprudencia más reciente sobre esta materia, como desarrollaremos a continuación:

2.- Sentencia de la Iltma. Corte de Apelaciones de Concepción. Rol 403-2006.

a) La I. Municipalidad de Yumbel otorgó en concesión a una empresa particular, el Balneario Salto del Laja; b) La Municipalidad le puso término anticipado a la concesión por incumplimientos graves del concesionario, en cuanto al abandono que se demostraba en el balneario y no cumplimiento de las condiciones de la concesión; c) La Corte consideró que la Municipalidad actuaba en el ejercicio de sus facultades al poner término anticipado a la concesión y rechazó el reclamo de ilegalidad interpuesto por el concesionario, estimando que el Municipio había actuado conforme a las facultades concedidas por el art. $8^{\circ}$ y 36 de la Ley 18.695, no incurriendo al respecto en ilegalidad alguna.

3.- Sentencia de la Iltma. Corte de Apelaciones de Santiago. Rol 5.626-2005.

a) La I. Municipalidad de Santiago otorgó una concesión a un grupo empresarial, para el diseño, fabricación, instalación y mantenimiento del mobiliario urbano y su explotación de publicidad; b) Se produjeron divergencias entre las partes que se zanjaron en una transacción judicial; c) La empresa concesionaria no pagó ninguna de las cuotas del convenio de pago suscrito con el municipio, conforme al art. 63 del DL N ${ }^{\circ}$ 3063; d) La Municipalidad estimó este incumplimiento constitutivo de una infracción grave, y puso término anticipado al contrato; e) La concesionaria dedujo reclamo de ilegalidad, el que fue rechazado por estimar el Tribunal que el municipio de Santiago había actuado conforme al art. 20.1 de las Bases Administrativas, que calificaba de infracción muy grave "el no pago de la renta de la concesión" y que por consiguiente el organismo edilicio no había incurrido en ilegalidad alguna ${ }^{11}$.

4.- Sentencia 24 de junio 2005, Corte Apelaciones de La Serena. Rol 160-2005 confirmado por Exma. Corte Suprema fallo 4 agosto 2005. Rol 3.293-2005.

Este fallo es bastante interesante ya que define la naturaleza de la concesión de servicio público, en que se entrega a un particular la gestión de un servicio público, su administración, y en algunos casos su construcción y habilitación, a cambio del cobro de una tarifa, que constituye el precio por la prestación del servicio.

\section{Conclusiones}

1.- El sistema normativo del régimen de concesiones establecido en los arts. $8^{\circ}, 36$, 37 y 65 letra j) de la Ley 18.695 está bien concebido. Resguarda tanto los intereses de los concesionarios como el interés público, en este caso a cargo de los municipios. Además guarda concordancia con los preceptos de la Ley 18.695 sobre Bases Generales

11 Ver “Jurisprudencia Judicial Municipal”. Puntolex ańo 2009. 
del Estado y Ley 19.880 sobre Procedimientos Administrativos, que constituyen el marco regulatorio del ordenamiento jurídico del Derecho Público.

2.- Al parecer pocas veces los conflictos y controversias entre Municipios y concesionarios llegan a conocimiento y resolución de los Tribunales, señal de que el sistema por lo general funciona satisfactoriamente.

3.- No obstante que existan reglas claras para poner término anticipado a las concesiones y en lo relativo a la procedencia de las indemnizaciones, resulta altamente conveniente que los Municipios sean especialmente cuidadosos al momento de aprobar las Bases del llamado a licitación pública. Es de suma conveniencia determinar con certeza las obligaciones del concesionario, señalar con precisión la calificación de las conductas que se considerarán constitutivas de incumplimiento grave, entre otras también la reiteración en forma continua o discontinua de conductas, que en forma aislada, solo representan incumplimientos menores, pero que siendo reiteradas se consideran incumplimientos graves.

4.- No debemos olvidar que el Municipio representa en estos casos los intereses de la comunidad local, por los cuales debe velar en todo momento, tras la consecusión del Bien común.

\section{Bibliografía}

1.- Jurisprudencia Judicial Municipal. Editorial Punto Lex S.A. Stgo. Año 2009. Departamento de Estudios Jurídicos Punto Lex.

2.- Derecho Municipal chileno. José Fernández Richard. Editorial Jurídica de Chile. Años 2003 y 2007.

3.- Las prerrogativas de la Administración en los contratos de las administraciones públicas. Jaime Rodríguez Arana.

4.- Derecho Administrativo chileno y comparado Enrique Silva Cimma. Editorial Jurídica de Chile. Año $1995 .{ }^{12}$

12 El autor de este trabajo lo es de las siguientes obras: "Las Patentes Municipales"; "Régimen Jurídico de la Administración Municipal", 2 ediciones; "Derecho Municipal chileno", 2 ediciones; "Derecho Urbanístico chileno", 2 ediciones. Editorial Jurídica de Chile. 